mutant genotype of winter oilseed rape // Plant Breeding. 2010. V. 129. P. 502-507.

3. Amosova A.V., Zemtsova L.V., Grushetskaya Z.E., Samatadze T.E., Mozgova G.V., Pilyuk Y.E., Volovik V.T., Melnikova N.V., Zelenin A.V., Lemesh V.A., Muravenko O.V. Intraspecific chromosomal and genetic polymorphism in Brassica napus L. detected by cytogenetic and molecular markers // Journal of Genetics. 2014. V. 93. P. 133-143.

4. Xiong Z.Y., Gaeta R.T., Pires J.C. Homoeologous shuffling and chromosome compensation maintain genome balance in resynthesized allopolyploid Brassica napus // Proceedings of the National Academy of Sciences USA. 2011. V. 108. P. 7908-7913.

5. Mason A.S., Snowdon R.J. Oilseed rape: learning about ancient and recent polyploid evolution from a recent crop species // Plant Biol (Stuttg). 2016. V. 18. P. 883-892.

6. Amosova A.V., Zemtsova L.V., Yurkevich O.Y., Zhidkova E.N., Książczyk T., Shostak N.G., Muravlev A.A., Artemyeva A.M., Samatadze T.E., Zoshchuk S.A., Muravenko O.V. Genomic changes in generations of synthetic rapeseed-like allopolyploid grown under selection // Euphytica. 2017. V. 213. P. 217-229.

7. Howell P.M, Marshal D.F, Lydiate D.J. Towards developing intervarietal substitution lines in Brassica napus using marker assisted selection // Genome. 1996. V. 39. P. 348358.

8. Barthes L., Ricroch A. Interspecific chromosomal rearrangements in monosomic addition lines of Allium // Genome. 2001. V. 44. P. 929-935.

DOI 10.18699/GPB2020-06

\title{
Изучение коллекции пшеницы мягкой яровой для выявления высокоурожайных источников устойчивых к комплексу болезней
}

Апарина В.A. ${ }^{l}$ *, магистрантка; Пискарев B.B. ${ }^{2}$, к.с.-х.н., зав. лаб. генофонда растений; Бойко Н.И. ${ }^{2}$, м.н.с.; Сухомлинов В.Ю. ${ }^{2}$, агроном 1 категории.

${ }^{1}$ ФБОУ ВО Новосибирский ГАУ, Новосибирск, Россия;

${ }^{2}$ СибНИИРС - филиал ИЦиГ СО РАН, Новосибирск, Россия

*e-mail: apari-na.viktoriya@yandex.ru

В результате оценки 158 коллекционных линий пиеницьы мягкой яровой в условиях 2019 года выделены образцы устойчивые к одному или нескольким заболеваниям с урожайностью выше или на уровне стандартов. Ранние сорта - Norm $\left(527,7\right.$ 2/ $\left.\mathrm{M}^{2}\right)$ и Kenуоп $(528,6)$; среднеранние и среднеспелье - Этюд (678,9), Свеча (606,2), CDC Merlin (610,5), Легенда $(660,2)$, Лютесиенс 503 (663,9), Харьковская 22 (527,8), PS 133 (568,9), Aletch $(558,1)$, NIL Thatcher Lr36 (469,3), Геракл (579,7), МИС (543,2), Омская 37 (548,5), Glenlea (465,8), AC Drummond (559,5), Cunnigharn (416,8), среднепоздниеМерцана (658,1), Воевода (686,5), Экада $6(545,7)$, Тулайковская $5(604,2)$, WW 17283 (574,1), Маргарита (558,6), Омская 38 (528,4), Nardo (560,3), Tyлайковская 110 (511,9), Тулайковская золотистая (507,3), Тулайковская 108 $(605,9)$, Rh 66-6 (590,5), Тулайковская $10(580,1)$, Экада 85 (593,2). Для подтверждения урожайных качеств линий необходимо продолжить изучение 
образиов.

Ключевые слова: пшеница мягкая яровая; устойчивость; источник; урожайность; сорт.

\section{Study of a collection of soft spring wheat for finding high-yielding sources resistant to a complex of diseases}

Aparina $V .{ }^{1}$, Piskarev $V .^{2}$, head of laboratory, Boiko $N^{2}$, junior researcher, Sukhomlinov $V .^{2}$, agronomist

${ }^{l}$ Federal State Budgetary Educational Institution of Higher Education "Novosibirsk State Agrarian University", Novosibirsk Russia

${ }^{2}$ SibRIPP\&B - branch ICG SB RAS, Novosibirsk, Russia.

As a result of the evaluation of 158 collection lines of soft spring wheat in the conditions of 2019, samples resistant to one or more diseases with a yield above or at the level of standards were identified. Early varieties - Norm $(527.7 \mathrm{~g}$ / m2) and Kenyon (528.6); middle-early and middle varieties - (678.9), Svecha (606.2), CDC Merlin (610.5), Legenda (660.2), Lutescens 503 (663.9), Kharkovskaya 22 (527.8), PS 133 (568.9), Aletch (558.1), NIL Thatcher Lr36 (469.3), Gerakl (579.7), MIS (543.2), Omskaya 37 (548.5), Glenlea (465.8), AC Drummond (559.5), Cunnigharn (416.8), mid-late varieties - Mertsana (658.1), Voivoda (686.5), Ekada 6 (545.7), Tulaykovskaya 5 (604.2), WW 17283 (574.1), Margarita (558.6), Omsk 38 (528.4), Nardo (560.3), Tulaykovskaya 110 (511.9), Tulaykovskaya Zolotistaya (507.3), Tulaykovskaya 108 (605.9), Rh 66-6 (590.5), Tulaykovskaya 10 (580.1), Ekada 85 (593.2). To confirm the yield qualities of the lines, it is necessary to continue studying the samples.

Пшеница подвержена воздействию большого комплекса фитопатогенов, среди которых возбудители бурой (Puccinia triticina Rob. ex Desm. f. sp. tritici Erikss. et Henn.) ржавчины и септориоза (Septoria tritici Rob. ex Desm.) занимают особое место [1].

Успех селекционной работы определятся правильным подбором исходного материала. Он является важным фактором формирования продуктивности, а также комплекса хозяйственно-ценных признаков современных сортов. Изучение и проработка коллекционного материала различного эколого-географического происхождения расширяет круг важных для селекционного процесса признаков, присущих данной культуре. В том числе образцы отличаются значительным генотипическим потенциалом устойчивости к фитопатогенам, что обусловлено микроэволюционными процессами формирования рассоспецифической устойчивости их генотипов в разных условиях среды.

Целью исследования является оценка урожайности коллекционных образцов яровой мягкой пшеницы, источников известных генов устойчивости к комплексу грибных болезней. 
В изучение включены 158 линий, отобранных из коллекционных образцов пшеницы мягкой яровой, сохраняемых в лаборатории генофонда растений СибНИИРС - филиала ИЦиГ СО РАН, устойчивые к одному или нескольким заболеваниям. Стандартами для групп спелости являлись: ранние - Новосибирская 15, среднеранние - Новосибирская 31 и среднепоздние Сибирская 17. Площадь делянки $2 \mathrm{~m}^{2}$, посев изучаемых образцов без повторений, стандартов в 4-х повторениях.

Предшественник - черный пар. Агротехника - принятая для яровой пшеницы [2]. Посев питомника проводили 10 мая 2019 г. сеялкой ССФК-7.

Оценка элементов продуктивности изучаемых линий пшеницы мягкой яровой проведена по методике ВИР [3], разработанной для изучения новых поступлений коллекционных образцов. В период вегетации растений отмечены фенологические фазы - всходы, колошение, восковая спелость. В фазу восковой спелости растения убраны в снопы и подвергнуты структурному анализу. Оценка поражения линий мягкой яровой пшеницы заболеваниями, распространенными в Западной Сибири, проводили в полевых условиях на естественном инфекционном фоне по методике ВИР [3].

В результате полевой оценки (группа ранних сортов, табл. 1) выделены образцы, с урожайностью выше стандарта (Новосибирская 15 - 437,2 $\left.\Gamma / \mathrm{M}^{2}\right) \operatorname{Norm}(527,7)$, Kenyon $(528,6)$, имеющие устойчивость к бурой ржавчине и септориозу (99 и 7б).

Таблица 1 - Показатели продуктивности и устойчивости образцов пшеницы мягкой яровой (ранние сорта)

\begin{tabular}{|c|c|c|c|c|c|c|}
\hline \multirow[t]{2}{*}{ Сорт } & \multicolumn{2}{|c|}{$\begin{array}{c}\text { Гены } \\
\text { устойчивости* }\end{array}$} & \multirow[t]{2}{*}{$\begin{array}{c}\text { Урожай- } \\
\text { ность, } \Gamma / \mathrm{M}^{2}\end{array}$} & \multirow[t]{2}{*}{$\begin{array}{l}\text { МР**, } \\
\text { балл }\end{array}$} & \multirow[t]{2}{*}{$\begin{array}{l}\text { БР**, } \\
\text { балл }\end{array}$} & \multirow{2}{*}{$\begin{array}{c}\text { Септо- } \\
\text { риоз, } \\
\text { балл } \\
\end{array}$} \\
\hline & $\mathrm{Lr}$ & $\mathrm{Pm}$ & & & & \\
\hline Новосибирская 15 & - & - & 437,2 & 3 & 5 & 5 \\
\hline Norm & $\operatorname{LrX}$ & $P m$ & 527,7 & 5 & 99 & 7 \\
\hline Kenyon & $L r 26$ & $P m 8$ & 528,6 & 3 & 99 & 7 \\
\hline HCP 05 & & & 78,5 & & & \\
\hline
\end{tabular}

*По литературным данным

**БР - поражение бурой ржавчиной, МР - поражение мучнистой росой.

В результате полевой оценки сортов, отнесенных к группе среднеранних (табл. 2), среди изученных образцов в сравнении со стандартом (Новосибирская $31-525,0$ г/м²) превышения по урожайности выявлены у сортов: Этюд $(678,9)$, Свеча $(606,2)$, CDC Merlin $(610,5)$, Легенда $(660,2)$, Лютесценс $503(663,9$ г/м²). Также выделены сорта с урожайностью на уровне со стандартом: Харьковская $22(527,8)$, PS $133(568,9)$, Aletch $(558,1)$, NIL Thatcher Lr36 (469,3), Геракл $(579,7)$, МИС $(543,2)$, Омская $37(548,5)$, Glenlea $(465,8)$, AC Drummond $(559,5)$, Cunnigharn $(416,8)$. 
Таблица 2 - Показатели продуктивности и устойчивости образцов пшеницы мягкой яровой (среднеранние сорта)

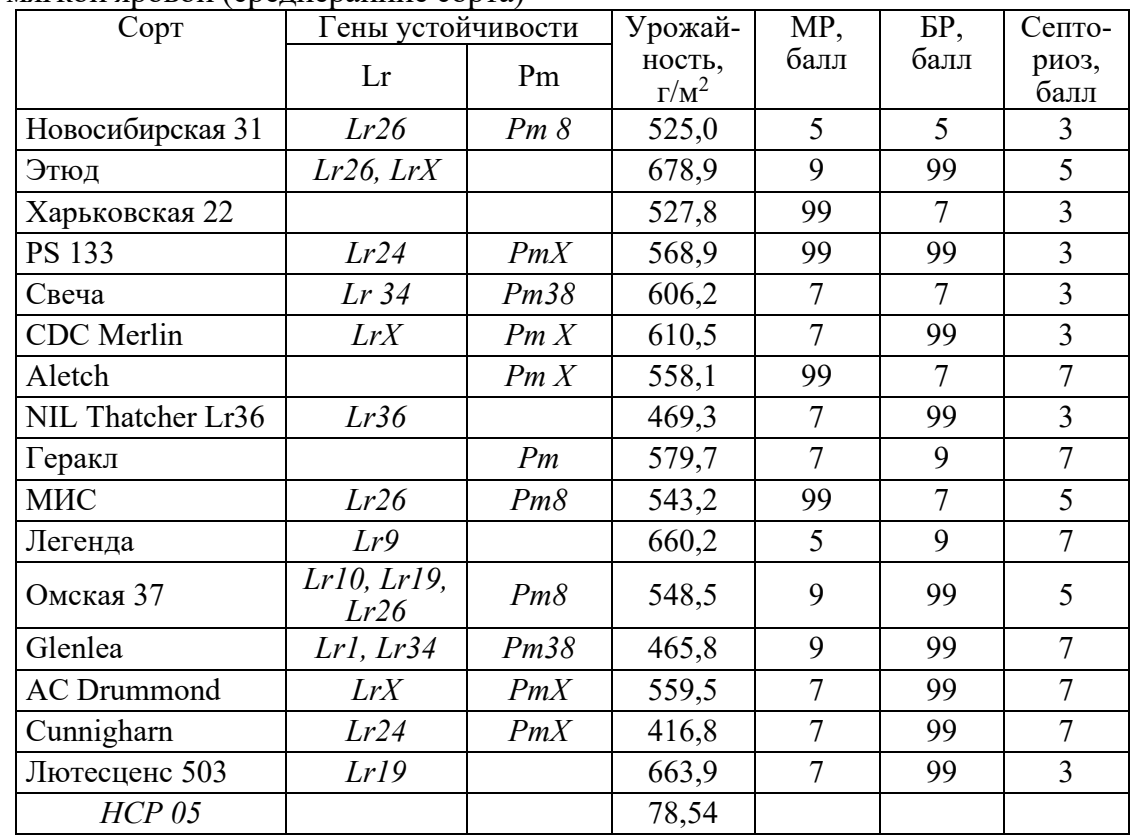

По устойчивости к основным заболеваниям (мучнистая роса, бурая ржавчина и септориоз пшеницы, устойчивость 7-99 баллов):

-комплексная устойчивость: Aletch, Геракл, Glenlea, AC Drummond, Cunnigharn.

-устойчивые к бурой ржавчине и септориозу: Легенда.

-устойчивые к мучнистой росе и бурой ржавчине: Этюд, Харьковская 22, PS 133, Свеча, CDC Merlin, NIL Thatcher Lr36, Мис, Омская 37, Лютесценс 503.

В результате полевой оценки сортов, отнесенных к группе среднепоздних сортов (табл. 3), выделены образцы превысившие по урожайности стандарт

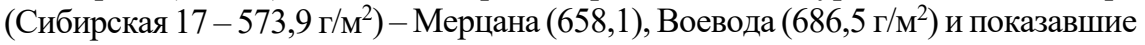
себя на уровне со стандартом: Экада $6(545,7)$, Тулайковская $5(604,2), \mathrm{WW}$ $17283(574,1)$, Маргарита $(558,6)$, Омская $38(528,4), \operatorname{Nardo}(560,3)$, Тулайковская $110(511,9)$, Тулайковская золотистая $(507,3)$, Тулайковская $108(605,9), \mathrm{Rh} 66-6$ $(590,5)$, Тулайковская $10(580,1)$, Экада $85(593,2)$. 
Таблица 3 - Показатели продуктивности и устойчивости образцов пшеницы мягкой яровой (среднепоздние сорта)

\begin{tabular}{|c|c|c|c|c|c|c|}
\hline \multirow[b]{2}{*}{ Сорт } & \multicolumn{2}{|c|}{ Гены устойчивости* } & \multirow{2}{*}{$\begin{array}{c}\text { Урожай- } \\
\text { ность, } \\
\Gamma / \mathbf{M}^{2}\end{array}$} & \multirow{2}{*}{$\begin{array}{l}\text { МР, } \\
\text { балл }\end{array}$} & \multirow{2}{*}{$\begin{array}{l}\text { БР, } \\
\text { балл }\end{array}$} & \multirow{2}{*}{$\begin{array}{c}\text { Септо- } \\
\text { риоз, } \\
\text { балл }\end{array}$} \\
\hline & $\mathrm{Lr}$ & $\mathrm{Pm}$ & & & & \\
\hline Сибирская 17 & $\operatorname{Lr} 9$ & $P m 5 a$ & 573,9 & 5 & 7 & 7 \\
\hline Экада 6 & Lr19 & $P m X$ & 545,7 & 7 & 99 & 7 \\
\hline Тулайковская 5 & Lr6Agi2 & Pm6Agi2 & 604,2 & 99 & 99 & 7 \\
\hline WW 17283 & Lr19 & $P m X$ & 574,1 & 99 & 99 & 7 \\
\hline Маргарита & $\begin{array}{l}\text { Lr49, Lr34, } \\
\text { Lr10 }\end{array}$ & Pm38 & 558,6 & 9 & 99 & 7 \\
\hline Омская 38 & Lr19, Lr26 & Pm8 & 528,4 & 5 & 9 & 7 \\
\hline Nardo & & $P m X$ & 560,3 & 7 & 7 & 7 \\
\hline Тулайковская 110 & Lr19+Lr6Agi1 & Pm6Agil & 511,9 & 99 & 99 & 7 \\
\hline $\begin{array}{l}\text { Тулайковская } \\
\text { Золотистая }\end{array}$ & Lr6Agi2 & Pm6Agi2 & 507,3 & 99 & 99 & 7 \\
\hline Тулайковская 108 & Lr19+Lr6Agi1 & Pm6Agil & 605,9 & 99 & 99 & 7 \\
\hline Мерцана & $\operatorname{LrX}$ & $P m X$ & 658,1 & 99 & 99 & 7 \\
\hline Rh 66-6 & $\operatorname{LrX}$ & & 590,5 & 5 & 99 & 7 \\
\hline Воевода & $\mathrm{LrBel}$ & PmAg.i & 686,5 & 99 & 99 & 7 \\
\hline Тулайковская 10 & Lr6Agi2 & Pm6Agi2 & 580,1 & 99 & 99 & 7 \\
\hline Экада 85 & $\operatorname{LrX}$ & $P m X$ & 593,2 & 99 & 99 & 5 \\
\hline HCP 05 & & & 78,54 & & & \\
\hline
\end{tabular}

По устойчивости к основным заболеваниям (мучнистая роса, бурая ржавчина и септориоз пшеницы, устойчивость 7-99 баллов):

-комплексная устройчивость: Экада 6, Тулайковская 5, WW 17283, Маргарита, Nardo, Тулайковская 110, Тулайковская золотистая, Тулайковская 108, Мерцана, Воевода, Тулайковская 10.

-устойчивые к бурой ржавчине и септориозу: Омская 38, Rh 66-6.

-устойчивые к мучнистой росе и бурой ржавчине: Экада 85.

\section{Список литературь}

1. Волкова Г.В. и др. Поиск сортообразцов пшеницы с групповой устойчивостью и их практическое использование // Труды по прикладной ботанике, генетике и селекции. - 2009. - Т. 166. - С. 33-41.

2. Доспехов Б.А. Методика полевого опыта (с основами статистической обработки результатов исследований) / Б.А. Доспехов. - 2-е изд., перераб. и доп. - М.: Колос, 1968. - 336 с.

3. Мережко А.Ф. и др. Пополнение, сохранение в живом виде и изучение мировой коллекции пшеницы, эгилопса и тритикале. Методические указания // СПб.: ВИР. $-1999 .-81 \mathrm{c}$. 